\title{
Parenting and Adolescents' Academic Achievement: The Mediating Role of Goal Engagement and Disengagement
}

\author{
Priscilla S. Yau $\mathbb{D}^{1} \cdot$ Yongwon $\mathrm{Cho}^{1} \cdot$ Jacob Shane $^{2} \cdot$ Joseph Kay $^{3} \cdot$ Jutta Heckhausen $^{1}$
}

Accepted: 13 June 2021 / Published online: 7 July 2021

(c) The Author(s) 2021

\begin{abstract}
Prior research has investigated parental behavior and students' motivation separately as predictors of adolescents' academic achievement. The current study jointly examined the associations between parental behavior, adolescents' motivation, and academic achievement. Using data collected from participants in youth programs $(N=220)$, we investigated whether students' academic goal engagement and disengagement mediates the association between adolescents' relationships with their parents and their academic achievement. Findings from regression-based mediation models indicated that adolescents' perceived maternal support was positively associated with their academic achievement, and that this association was mediated by students' engagement with academic goals. Perceived maternal psychological control was negatively associated with students' academic success, mediated by students' academic goal disengagement. Supplementary analyses examining components of perceived parental support and psychological control showed that maternal warmth may be most beneficial for adolescents' academic success, whereas maternal devaluation may be most detrimental. Perceived paternal psychological control was only associated with lower academic achievement, but was not related to adolescents' goal disengagement.
\end{abstract}

Keywords Parental support $\cdot$ Parental psychological control $\cdot$ Academic engagement $\cdot$ Academic disengagement $\cdot$ Academic achievement

\section{Highlights}

- Adolescents' academic goal engagement positively mediated the relation between maternal support and academic achievement.

- Adolescents' academic goal disengagement negatively mediated the association between maternal psychological control and academic achievement.

- Results suggest ways in which mothers can either promote or hinder adolescents' academic achievement.

Research has widely shown that parents play an important role in adolescents' academic performance (Froiland \& Worrell, 2017; Pinquart, 2016; Pinquart \& Ebling, 2020;

Priscilla S. Yau

psyau@uci.edu

1 Department of Psychological Science, University of California, Irvine, 4201 Social \& Behavioral Sciences Gateway, Irvine, CA 92697-7085, USA

2 Department of Psychology, Brooklyn College, The City University of New York, 2900 Bedford Ave, Brooklyn, NY 11210, USA

3 Behavior Change for Good Initiative, University of Pennsylvania, Philadelphia, 3451 Walnut St, Philadelphia, PA 19104, USA
Wang et al., 2018), yet less is known about the mechanisms through which this occurs. The purpose of our study is to examine: (1) which parenting characteristics are related to adolescents' academic achievement, and (2) whether adolescents' motivational academic goal engagement and disengagement mediate the association between parenting and academic achievement.

\section{Positive Parenting and Academic Success}

Parents' expectations, beliefs, and behaviors are strongly associated with students' academic achievement (Abar et al., 2009; Boonk et al., 2018; Dornbusch et al., 1987; Englund et al., 2004; Gordon \& Cui, 2012; Hill et al., 2004; 
Roksa \& Potter, 2011). More specifically, prior research has found that parenting practices with supportive characteristics such as being highly responsive and setting up clear rules are the most effective in facilitating children's academic achievement (Aunola et al., 2000; Baumrind, 1966; Brown \& Iyengar, 2008; Woolley et al., 2009). Many studies also have shown that supportive parenting characteristics, including warmth (i.e., expressing love towards the child), involvement (i.e., spending time with the child), and autonomy-support (i.e., guiding the child towards independence), are positively linked to academic success (Pinquart, 2016; Gonida \& Cortina, 2014; Froiland \& Worrell, 2017; Henry \& Plunkett et al., 2011; Topor et al., 2010; Wang et al., 2014; Wang \& Sheikh-Khalil, 2014). Combining these findings, Pinquart (2016) conducted a metaanalysis and showed wide-spread evidence for significant associations between supportive parenting characteristics and adolescents' academic achievement. Our study will focus on the combination of parental warmth, involvement, and autonomy-support, referred to as parental support. Building on the evidence linking parental support with academic achievement, we examine motivational mechanisms as potential mediators between supportive parenting and children's academic achievement.

\section{Negative Parenting and Academic Difficulties}

In addition to positive supportive parenting, negative parenting characteristics are also associated with academic and developmental outcomes in children and adolescents (e.g., Garcia \& Serra, 2019; Sangawi et al., 2018). Negative parenting is not defined merely as an absence of parental support, but rather as different parenting strategies that have potentially detrimental consequences for adolescents (e.g., Xiang et al., 2017). One of the potentially harmful strategies is parental psychological control, which refers to parents' attempts to manipulate and control their children's thoughts and behavior (Barber, 1996). Constructs of parental psychological control consist of multiple components, including devaluation (i.e., invalidating the child's thoughts and expressions) and guilt induction (i.e., causing the child to feel guilty) (Tian et al., 2019). Some parents use psychological control so children will remain emotionally dependent on them (Symeou \& Georgiou, 2017).

In the context of academic achievement, psychological control has been found to be negatively associated with academic success (e.g., Aunola \& Nurmi, 2004; Pinquart, 2016). Psychological control can be especially harmful for adolescents because as they approach the transition into adulthood they are in the process of developing their selfconcept of competence and identity, consequently feeling more vulnerable to social influences that may undermine their sense of autonomy and self-worth (Symeou \& Georgiou, 2017). For example, Lu et al. (2017) found that adolescents who experienced strong parental attempts for psychological control had low academic self-concept. Numerous studies have also shown a negative association between parental psychological control and adolescents' academic self-efficacy and academic performance (Desjardins \& Leadbeater, 2017; Xu et al., 2020). Building on this research that has revealed associations between parental psychological control and adolescents' academic outcomes, we will further investigate the mechanisms through which this effect occurs.

\section{Goal Engagement, Goal Disengagement, and Academic Achievement}

One of the crucial processes that are involved in adolescents' educational pursuit is goal engagement (Hall et al., 2006; Hamm et al., 2013). According to the motivational theory of lifespan development (Heckhausen et al., 2010), individuals actively contribute to their development through the coordination of both motivational engagement and disengagement. Goal engagement is defined as the behavioral strategy of investing time and effort into achieving a goal and the use of cognitive strategies of intentional goal commitment that includes avoiding distraction, enhancing perceptions of control, and imagining positive affect with goal attainment. By enhancing and maintaining their goal commitment, individuals are able to persist in their pursuit of desired goals, such as outstanding achievement in school (Heckhausen \& Schulz, 1995). Investing time and effort into schoolwork is one of the main factors that determine academic success (Hall et al., 2006), and internally maintaining goal focus, especially under challenging conditions (Hamm et al., 2013) or severely negative life events (Poulin \& Heckhausen, 2007), facilitates the behavioral strategies needed to achieve in school.

Conversely, when individuals feel they are not in control of their goal attainment or may not be able to attain their goals, they may disengage from pursuing them (Heckhausen et al., 2010). While goal disengagement may be a beneficial strategy in circumstances in which the goal is truly unattainable (Rothermund \& Brandstädter, 2003; Wrosch \& Scheier, 2020), individuals experience detrimental effects when they disengage from goals prematurely. When individuals disengage from goals too early, they are not investing substantial effort, persisting in the face of setbacks, or remaining optimistic about attainability of the goal (Freund \& Baltes, 1998; Komarraju \& Nadler, 2013; Monzani et al., 2015). This may be particularly damaging for the pursuit of academic goals during 
high school, as high school academic achievement strongly predicts postsecondary educational attainment (Galla et al., 2019). To promote goal engagement and prevent adolescents from pre-maturely disengaging from their academic goals, we aim to understand factors that facilitate adolescents' academic goal engagement and disengagement.

\section{Goal Engagement and Disengagement as Mediators Between Parenting and Academic Achievement}

Prior studies have examined the indirect relation between parenting and academic achievement through a few motivational factors as mediators (e.g., Guay et al., 2013; Pinquart \& Ebling, 2020). For example, Lowe and Dotterer (2013) found that parental warmth was positively associated with adolescents' academic motivation, resulting in better academic outcomes. Other motivational factors such as students' perception of control, academic self-concept, and intrinsic motivation have been shown to mediate the relation between parenting and academic achievement (Fulton \& Turner, 2008; Guay et al., 2013; Pinquart \& Ebeling, 2020). On the other hand, adolescents with controlling parents are less likely to maintain cognitive engagement with academic goals, resulting in lower academic achievement (Markazi \& Badrigargari, 2011). Despite the findings, no known studies have assessed the association between parenting characteristics and adolescents' academic goal engagement and disengagement, which are crucial for academic outcomes. Hence, our study aims to fill this gap by examining how adolescents' use of motivational academic engagement and disengagement may explain the mechanism through which parenting and academic achievement are associated.

\section{Differential Effects of Mothers and Fathers}

While numerous studies have assessed parenting by combining the effects of mothers and fathers (e.g., Gonida \& Cortina, 2014; Froiland \& Worrell, 2017, Wang et al., 2014), other studies have highlighted differences between mothers' and fathers' influence on their children's academic outcomes through examining the effects of each parent separately (e.g., Henry et al., 2011; Hill, 2015; Hsu et al., 2011; Lowe \& Dotterer, 2013). For example, Hsu et al. (2011) found that among Taiwanese parents, mothers had greater involvement in adolescents' education than fathers. In addition, mothers' involvement was a stronger predictor of academic achievement than fathers' involvement. Henry et al. (2011) found that among Latinx adolescents, their perception of mothers' educational aspirations predicted their GPA, but fathers' educational aspirations did not. On the other hand, meta-analyses have found a positive association between fathers' involvement and various developmental outcomes (Jeynes, 2015), and have emphasized the need for studies to identify the distinct ways in which mothers and fathers contribute to their children's academic achievement (Hill, 2015). To further investigate the role played by both mothers and fathers in adolescents' educational pursuits, the present study examined parenting dimensions separately for mothers and fathers.

\section{Current Study}

Many studies have explored direct and indirect associations between parenting, adolescents' motivation, and academic achievement (e.g., Lowe \& Dotterer, 2013; Pinquart, 2016; Wang \& Sheikh-Khalil, 2014). However, studies have yet to examine whether adolescents' academic goal engagement and disengagement may mediate the association between parenting and adolescents' academic achievement; our study aims to do so. Based on prior research, we expect that adolescents' academic goal engagement will positively mediate the relation between parental support and adolescents' academic achievement for both mothers (Hypothesis 1a) and fathers (Hypothesis 1b). In contrast, adolescents' academic goal disengagement is expected to mediate the negative relation between parental psychological control and adolescents' academic achievement for both mothers (Hypothesis 2a) and fathers (Hypothesis 2b). To determine which parenting characteristic is driving the association between parenting and academic achievement via adolescents' goal engagement and goal disengagement, sub-factors of parental support and psychological control will also be examined.

\section{Method}

\section{Participants and Procedure}

Data was collected from 244 high school students in grades 9-12 at four different afterschool programs and one in-school program in Southern California. A total of 220 participants were retained in the analyses after accounting for missing data and using multiple imputation for all variables of interest. The remaining missing data was from demographic variables, and 24 participants who did not have complete data on demographics were excluded from the study. Little's MCAR test (Little, 1988) showed that data was missing completely at random $(\chi 2(100)=102.06, p=0.424)$, and multiple imputation was conducted to infer the missing values from existing observations in non-categorical variables (Li et al., 2015). Results did not change when analyses were run using the imputed data. Missing values occurred 
Table 1 Descriptives for parenting and demographic variables

\begin{tabular}{|c|c|c|c|c|c|}
\hline & $\mathrm{N}$ & Minimum & Maximum & Mean & $\begin{array}{l}\text { Std. } \\
\text { Deviation }\end{array}$ \\
\hline Mothers' Support & 220 & 1.04 & 5.00 & 3.84 & 0.82432 \\
\hline Fathers' Support & 220 & 1.22 & 5.00 & 3.49 & 0.88054 \\
\hline $\begin{array}{l}\text { Mothers' } \\
\text { Psychological } \\
\text { Control }\end{array}$ & 220 & 1.00 & 3.00 & 1.75 & 0.55573 \\
\hline $\begin{array}{l}\text { Fathers' } \\
\text { Psychological } \\
\text { Control }\end{array}$ & 220 & 1.00 & 3.00 & 1.70 & 0.53541 \\
\hline $\begin{array}{l}\text { Academic } \\
\text { Achievement }\end{array}$ & 220 & 1.00 & 6.00 & 4.24 & 1.5163 \\
\hline Goal Engagement & 220 & 1.00 & 5.00 & 4.09 & 0.59830 \\
\hline $\begin{array}{l}\text { Goal } \\
\text { Disengagement } \\
\text { (Covariates) }\end{array}$ & 220 & 1.00 & 5.00 & 2.92 & 0.86312 \\
\hline \multicolumn{6}{|l|}{ Grade } \\
\hline Freshmen & 65 & & & & \\
\hline Sophomore & 75 & & & & \\
\hline Junior & 34 & & & & \\
\hline Senior & 46 & & & & \\
\hline \multicolumn{6}{|l|}{ Gender } \\
\hline Male & 84 & & & & \\
\hline Female & 136 & & & & \\
\hline \multicolumn{6}{|l|}{ Ethnicity } \\
\hline Whites & 24 & & & & \\
\hline Latinx & 173 & & & & \\
\hline Others & 23 & & & & \\
\hline \multicolumn{6}{|l|}{ Parental Education } \\
\hline $\begin{array}{l}\text { Less than } \\
\text { high school }\end{array}$ & 78 & & & & \\
\hline $\begin{array}{l}\text { High school } \\
\text { completion }\end{array}$ & 70 & & & & \\
\hline $\begin{array}{l}\text { More than } \\
\text { high school }\end{array}$ & 72 & & & & \\
\hline
\end{tabular}

most frequently for paternal psychological control (11.1\%), paternal support $(9.4 \%)$, and parental education $(9.8 \%)$. As $17 \%$ of participants lived with their mothers only, this may have contributed to a lack of responses for variables relating to fathers. However, results regarding paternal support did not change when analyses were conducted by excluding participants who did not live with their fathers. Participant demographics are presented in Table 1.

All data was collected at one time point. Students and their parents received study information sheets, and those who were interested in participating completed the survey after the parent signed an informed consent form and the adolescent signed an assent form. The survey took approximately 45 minutes to complete, and participants were compensated with a \$10 Amazon or Starbucks gift cards upon completion.
All procedures were approved by the University of California, Irvine Institutional Review Board.

\section{Measures}

\section{Parental Support}

The Perception of Parenting-College Student Scale (POPCSS) was used to measure perceived parental support (Niemiec et al., 2006). The POP-CSS was used instead of the original Perception of Parenting Scale because the latter scale has been mainly used and validated for children, even those as young as 8-years old (Grolnick et al., 1991). In noticing the similarity of items between the two scales, we used the one adapted for college students because it directly asks about their perceived relationship with their parents and the phrasing of the items is more specific. For example, one item in the original POP scale states, "some mothers always have enough time to talk to their children," while the item adapted for college students states, "my mother seems to know how I feel about things." Nevertheless, the use of the college scale will be mentioned in the Limitations section. The POP-CSS is a 42-item measure (21 items for mothers and 21 items for fathers), with a 5-point Likert scale ranging from "not at all true" to "very true." A 6-item subscale was used to measure parental warmth, with examples including that the mother or father "is typically happy to see me" or "accepts me and likes me as I am." The internal consistency for both mothers' warmth $(\alpha=0.86)$ and fathers' warmth $(\alpha=0.85)$ was good. To measure parental involvement, a 6-item subscale was also used, with sample items including that the parent "puts time and energy into helping me" or "spends a lot of time with me." Internal consistency for mothers' involvement $(\alpha=0.77)$ and fathers' involvement $(\alpha=0.75)$ was acceptable. To measure parental autonomy support, a 9-item subscale was used. A sample item is that the parent "helps me to choose my own direction," and internal consistency for mothers' $(\alpha=0.85)$ and fathers' autonomy support $(\alpha=0.83)$ was also good. However, due to the high collinearity among the subscales (see Table 2), we combined the subscales for our main analyses and labeled them as "maternal support" and "paternal support". When all three subscales were combined, the internal consistency was excellent for both maternal support $(\alpha=0.92)$ and paternal support $(\alpha=0.92)$. We also examined the contribution of each subscale on the outcome variables in the exploratory analysis section.

\section{Parental Psychological Control}

To measure psychological control, the Psychological Control Scale-Youth Report (PCS-YR) was used (Barber, 1996). This is an 8-item measure for both mothers and 


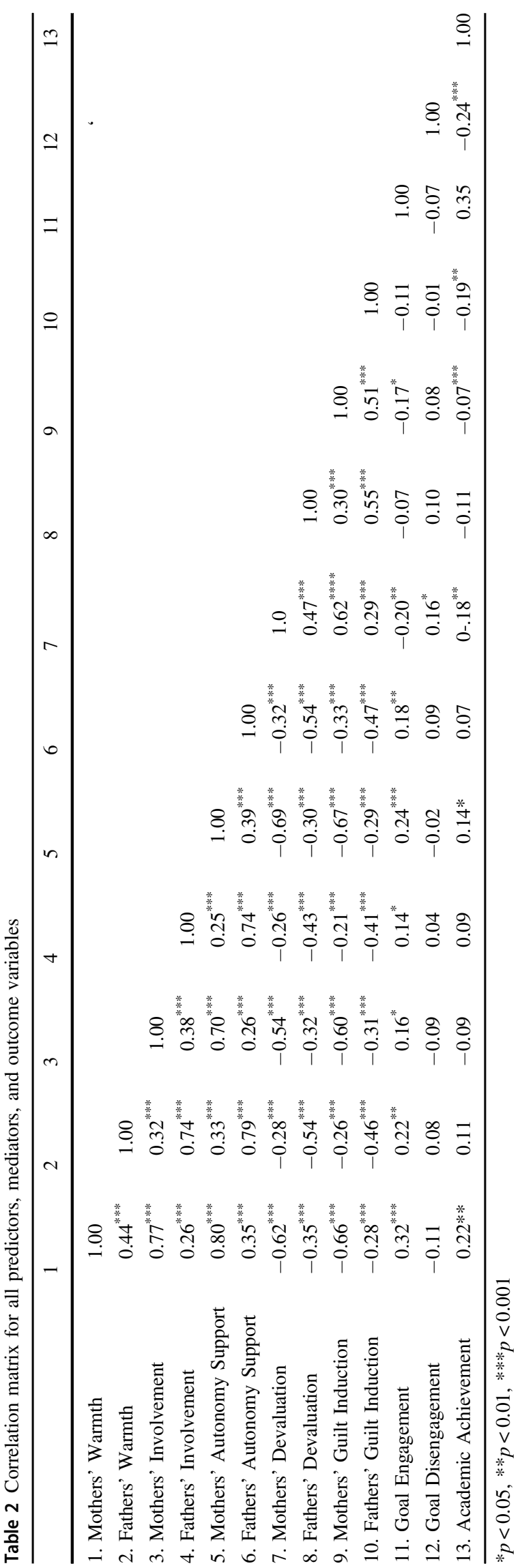

fathers, with a 3-point Likert scale ranging from "not like her/him" to "a lot like her/him." Devaluation and guilt induction were included as two subscales of psychological control. Devaluation consisted of 6 items for both mothers $(\alpha=0.82)$ and fathers $(\alpha=0.83)$, while guilt induction consisted of 2 items for mothers $(\alpha=0.66)$ and fathers $(\alpha=$ 0.71). A sample item of devaluation is that the mother or father "finishes my sentences whenever I talk," and an example of guilt induction is the mother or father "blames me for other family members' problems." The subscales in our dataset indicated high collinearity, and we combined the subscales to label them as "maternal psychological control" and "paternal psychological control". When these two subscales were combined, the internal consistency for maternal psychological control $(\alpha=0.85)$ and maternal psychological control $(\alpha=0.85)$ were high. In the exploratory analysis section, we examined the different roles of each subscale.

\section{Academic Goal Engagement and Goal Disengagement}

Education-specific Optimization of Primary and Secondary Control Scale (OPS) was used to measure motivational goal engagement and goal disengagement strategies (Heckhausen and Tomasik, 2002). The 9-item scale contained 5 items reflecting behavioral engagement (e.g., I will put time and effort into my education whenever I can") and 4 items reflecting cognitive engagement (e.g., "I often tell myself that I will be successful in reaching my educational goals"). Responses from the 5-point Likert scale ranged from "strongly disagree" to "strongly agree," and they were averaged to produce the composite goal engagement measure $(\alpha=0.84)$. Four items relating to goal adjustment (e.g., "If I have trouble with homework, I will adjust my goals so they are more realistic") and goal disengagement (e.g., "If I cannot attain my educational goals, I will let go of them") were averaged to create the goal disengagement measure $(\alpha$ $=0.61$, which has been validated and used in multiple studies (e.g., Heckhausen et al., 1998; Heckhausen and Tomasik, 2002). All items from the 5-point Likert scale included responses ranging from "strongly disagree" to "strongly agree."

\section{Academic Achievement}

Participants were asked to report their grades using a 6-point Likert scale, ranging from "Mostly lower than C's" to "Mostly A's."

\section{Demographics}

Participants reported their gender $(1=$ Male, $2=$ Female $)$, parental education, and ethnicity. Mothers' and fathers' 
parental education were coded into three ordinal levels $(1=$ less than high school, $2=$ high school completion, $3=$ more than high school). The highest of the two education scores between the parents was used, while the existing score was used when either the mother's or father's scores was missing. Ethnicity was categorized into three groups (Whites, Latinx, and Other), with each group dummy-coded.

\section{Analytical Plan}

A regression-based mediation model was conducted using maternal support as a predictor, academic goal engagement as a mediator, and adolescents' academic achievement as an outcome measure to test hypothesis 1a. Hypothesis $1 \mathrm{~b}$ was tested by including paternal support as a predictor in the second regression-based mediation model. Hypothesis $2 \mathrm{a}$ was tested through a third regression-based mediation model to determine whether academic goal disengagement mediated the relation between maternal psychological control and academic achievement, and a fourth regressionbased mediation model was conducted using paternal psychological control as a predictor to test hypothesis $2 \mathrm{~b}$.

For our supplementary analysis, we explored the role of parental support and parental psychological control subfactors. We used an additional mediation model to examine the indirect effects of specific sub-factors of parental support (warmth, involvement, and autonomy support from mothers and fathers) and psychological control (devaluation and guilt induction from both mothers and fathers) on academic achievement mediated by academic goal engagement and academic goal disengagement.

Mediation testing procedures were conducted both by using the causal-steps approach, a four-step approach in which several OLS regression analyses are conducted with the significance of the coefficients examined at each step (Baron and Kenny, 1986), and by using the bootstrapping of indirect effects approach (Shrout \& Bolger, 2002). The bootstrap sample was set at 5000 and the significant confidence interval was set at $95 \%$. A bootstrapped $95 \%$ CI that did not contain zero meant that there was a significant indirect effect (Hayes, 2017). Mediation was only tested if each of the steps in the causal-steps approach were satisfied. In all models, participants' age, gender, ethnicity and parental education were controlled as covariates. SPSS version 24.0 using PROCESS macro was used to test the mediation models (Hayes, 2017), and SPSS version 24.0 was also used for all other models.

Due to the limitation of determining directionality with a cross-sectional dataset, alternative models were tested to support the robustness of the model pertaining to the hypotheses. It is possible that the association between parenting and academic achievement is bidirectional and parents are responding to adolescents' academic achievement (e.g., Silinskas et al., 2013). To address this issue, we tested whether academic achievement predicted parenting.

\section{Results}

Descriptive statistics and bivariate correlations among the variables of interest are shown in Table 1 and Table $2(\mathrm{~N}=$ 220). The correlation patterns showed that the variables of interest were associated with the expected directions.

\section{Goal Engagement Mediating the Association Between Parental Support and Academic Performance}

Hypothesis 1a was tested using a series of regression models that assessed whether the relation between maternal support and academic achievement was mediated by academic goal engagement. Participants' grade, gender, ethnicity, and parental education level were included as covariates in each regression model.

Following the four-step approach by Baron and Kenny (1986), the first step showed that maternal support was positively associated with academic achievement (C-path: $\beta=0.18, p=0.007)$. In the second step, we found a positive association between mothers' support and adolescents' goal engagement (A-path: $\beta=0.29, p<0.001$ ). In the third step, goal engagement was positively associated with academic achievement (B-path: $\beta=0.34, p<0.001$ ). Maternal support was no longer directly associated with academic achievement when controlling for goal engagement ( $C$ 'path: $\beta=0.09, p=0.196)$. According to the causal-steps approach (Baron and Kenny, 1986), this pattern of results suggests that goal engagement fully mediates the relation between maternal support and academic achievement. Mediation was next assessed using the bootstrapping of indirect effect approach (Shrout \& Bolger, 2002). The standardized indirect effect from maternal support to academic achievement via goal engagement was 0.10. This indirect effect was tested for significance using a bootstrap approach that employed $95 \%$ bias corrected confidence intervals based on 5000 samples of the indirect effects. Results showed that the $95 \%$ confidence interval did not contain zero $(95 \%$ CI $[0.034,0.172])$, which indicated that the indirect effect from parental support to academic achievement via academic engagement was significant (Hayes, 2017). The regression-based mediation model explained $17.33 \%$ of the total variance in adolescents' academic achievement (Miočević et al., 2018). The results are depicted in Table 3 and Figure 1, and support hypothesis $1 \mathrm{a}$ in that academic goal engagement mediated the relation between maternal support and academic achievement. 
A total effect test was conducted for hypothesis $1 \mathrm{~b}$, and the first step of the four-step approach showed that paternal support was not significantly associated with academic achievement (C-path: $\beta=0.14, p=0.055$ ). Thus, we did not proceed to test whether adolescents' goal engagement mediated the relation between paternal support and academic achievement using the causal steps approach.

Table 3 Regression-based mediation model for association between maternal support and academic achievement via goal engagement

\begin{tabular}{|c|c|c|c|c|c|}
\hline Variables & $b$ & $S E$ & $\beta$ & $t$ & $p$ \\
\hline \multicolumn{6}{|c|}{ Model 1 Outcome variable $=$ Goal Engagement } \\
\hline (constant) & 3.25 & 0.29 & & 11.37 & $<0.001$ \\
\hline Maternal Support & 0.21 & 0.05 & 0.29 & 4.38 & $<0.001$ \\
\hline Grade & 0.04 & 0.04 & 0.08 & 1.22 & 0.223 \\
\hline Gender & 0.06 & 0.08 & 0.05 & 0.83 & 0.409 \\
\hline \multicolumn{6}{|l|}{ Ethnicity } \\
\hline White & 0.16 & 0.13 & 0.09 & 1.23 & 0.219 \\
\hline Other & -0.30 & 0.13 & -0.15 & -2.23 & 0.027 \\
\hline \multirow[t]{2}{*}{ Parental Education } & -0.07 & 0.05 & -0.10 & -1.35 & 0.177 \\
\hline & \multicolumn{5}{|c|}{$F(6,213)=5.40, p<0.001, R^{2}=0.132$} \\
\hline \multicolumn{6}{|c|}{ Model 2 Outcome variable $=$ Academic Achievement } \\
\hline (constant) & -1.38 & 0.90 & & -1.54 & 0.126 \\
\hline Maternal Support & 0.16 & 0.12 & 0.09 & 1.30 & 0.196 \\
\hline Goal Engagement & 0.85 & 0.17 & 0.34 & 5.06 & $<0.001$ \\
\hline Grade & 0.11 & 0.09 & 08 & 1.24 & 0.216 \\
\hline Gender & 0.42 & 0.20 & 0.14 & 2.14 & 0.033 \\
\hline \multicolumn{6}{|l|}{ Ethnicity } \\
\hline Whites & 0.17 & 0.33 & 0.03 & 0.51 & 0.612 \\
\hline Others & 0.14 & 0.33 & 0.03 & 0.41 & 0.679 \\
\hline \multirow[t]{2}{*}{ Parental Education } & 0.27 & 0.13 & 0.15 & 20.03 & 0.043 \\
\hline & \multicolumn{5}{|c|}{$F(7,212)=6.35, p<0.001, R^{2}=0.173$} \\
\hline
\end{tabular}

$b, S E, \beta, t$, and $p$ respectively indicate unstandardized coefficient, standard error, standardized coefficient, $\mathrm{t}$ statistics, and probability statistics. When controlling for ethnicities as a covariate, Latinx was treated as the reference group. For gender, male was coded as " 1 " and female was coded as " 2 "'

\section{Goal Disengagement Mediating the Association Between Psychological Control and Academic Achievement}

To test hypothesis $2 \mathrm{a}$ and $2 \mathrm{~b}$, we conducted a series of regressions to test whether goal disengagement mediated the association between perceived parental psychological control and adolescent academic achievement. Participants' grade, gender, ethnicity, and parental education level were included as covariates in each regression model.

The total effect test between maternal psychological control and academic achievement was conducted as step one of the casual steps approach (Baron and Kenney, 1986). Results showed that maternal psychological control was negatively associated with academic achievement (C-path: $\beta=-0.19, p=0.005)$. Step two showed that maternal psychological control was positively associated with goal disengagement (A-path: $\beta=0.18, p=0.008$ ). In step three, we found that goal disengagement negatively predicted academic achievement (B-path: $\beta=-0.20, p=0.003$ ). Maternal psychological control remained positively associated of academic achievement when goal disengagement was controlled in the model (C'-path: $\beta=-0.16, p=$ 0.021). According to the causal steps approach (Baron and Kenny, 1986), this pattern of results indicates that the relation between parental psychological control and adolescent academic achievement was partially mediated by academic goal disengagement. Mediation was further examined using the bootstrapping of indirect effect approach (Shrout \& Bulger, 2002). The standardized indirect effect from maternal psychological control to adolescent academic achievement via goal disengagement was -0.04 . Standardized indirect effects were computed for each of 5000 bootstrapped samples to form a $95 \%$ confidence interval of the estimate. The $95 \%$ confidence interval did not contain zero (95\% CI $[-0.078,-0.005]$ ), indicating that the indirect effect was statistically significant (Hayes, 2017). The regression-based mediation model explained $11.41 \%$ of the total variance in adolescents' academic achievement (Miočević et al., 2018). The results are presented in Table 4 and Figure 2, and collectively support hypothesis $2 \mathrm{a}$ in suggesting that goal
Fig. 1 Standardized regression coefficients for the association between parental support and academic achievement as mediated by goal engagement, controlling for gender, ethnicity, parental education, and grade. Note. $* p<0.05, * * p<0.01$, $* * * p<0.001$

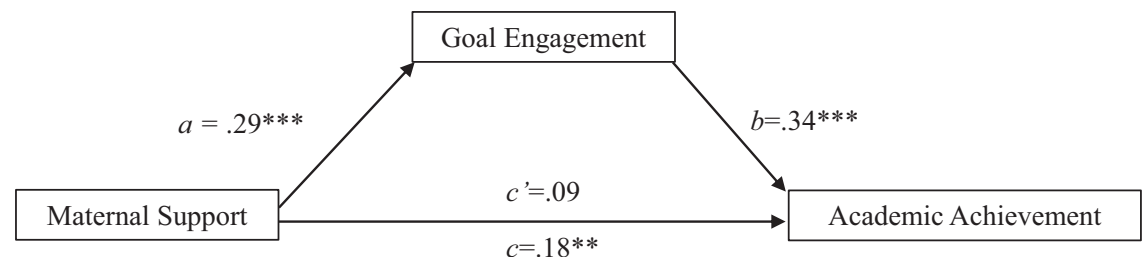

Indirect effect $=.10,95 \%$ CI $[.034, .172]$ 
disengagement at least partly mediates the relation between maternal psychological control and lower academic achievement.

Table 4 Regression-based mediation model for association between maternal psychological control and academic achievement via goal disengagement

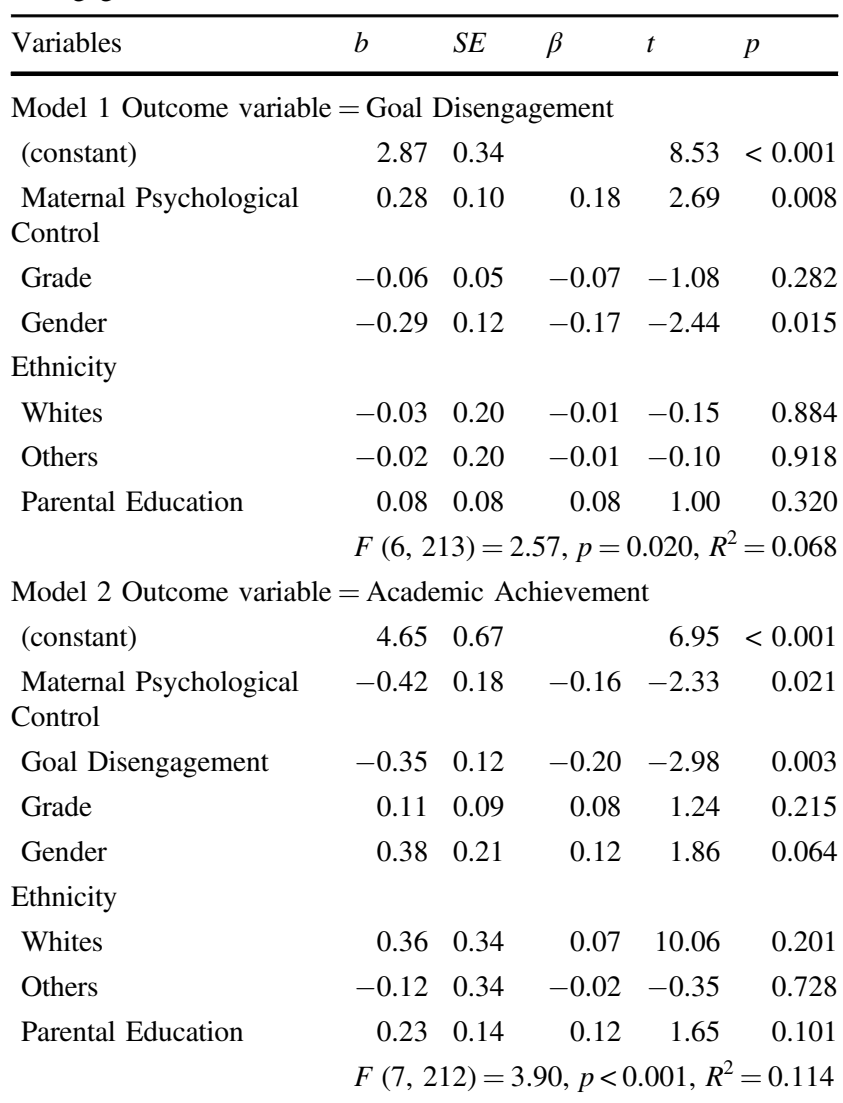

$b, S E, \beta, t$, and $p$ respectively indicate unstandardized coefficient, standard error, standardized coefficient, $\mathrm{t}$ statistics, and probability statistics. When controlling for ethnicities as a covariate, Latnix was treated as the reference group. For gender, male was coded as " 1 " and female was coded as " 2 "
For hypothesis $2 b$, the first step of the causal steps approach showed that paternal psychological control was negatively associated with academic achievement (B-path: $\beta=-0.18, p=0.011)$. However, step two showed that paternal psychological control did not significantly predict adolescents' goal disengagement (A-path: $\beta=0.11$, $p=0.109)$. Thus, we did not proceed to test whether adolescents' goal disengagement mediated the relation between fathers' psychological control and academic achievement, and hypothesis $2 \mathrm{~b}$ was not supported.

\section{Exploratory Analysis of Subscales of Parental Support and Psychological Control}

To better understand why goal engagement may mediate the association between parental support and academic achievement, we conducted a series of mediation analyses using the subscales that measured parental support (i.e., warmth, involvement, and autonomy support) as predictors, academic achievement as an outcome variable, and goal engagement as a mediator for mother and fathers. As step one of the casual steps approach of mediation testing, maternal support subscales were entered as predictors with academic achievement as the outcome (C-path) (Baron and Kenney, 1986). We found that only mothers' warmth was positively associated with academic achievement $(\beta=0.32$, $p=0.012)$, while mothers' involvement $(\beta=-0.18, p=$ $0.095)$, and mothers' autonomy support $(\beta=0.05, p=$ 0.658 ) were not significantly associated with academic achievement. Therefore, only mother's warmth was entered as a predictor in the second step. Step two results showed that mothers' warmth was positively associated with adolescents' goal engagement (A-path: $\beta=0.33, p<0.001$ ), and adolescents' goal engagement was positively associated with academic achievement (B-path: $\beta=0.33, p<0.001$ ). Mothers' warmth no longer predicted academic achievement when goal engagement was controlled in the model (C'-path: $\beta=0.11, p=0.101)$, indicating the relation was
Fig. 2 Standardized regression coefficients for the association between psychological control and academic achievement as mediated by goal disengagement, controlling for gender, ethnicity, parental education, and grade. Note. $* p<0.05, * * p<0.01, p<0.001$

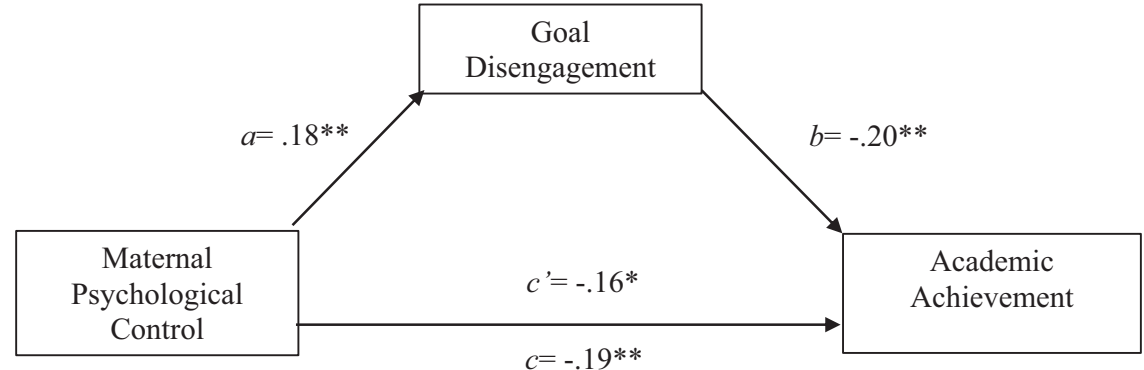

Indirect effect $=-.04,95 \%$ CI $[-.078,-.005]$ 
fully mediated. The standardized indirect effect via the mediation was 0.11 and significant (95\% CI [0.044, 0.188]) (Hayes, 2017). In addition to the statistically significant effect size of 0.11 , the mediation-based regression model explained $10.94 \%$ of the total variance in adolescents' academic achievement (Miočević et al., 2018). On the other hand, no paternal support subscales were tested to be significantly associated with academic achievement (fathers' warmth: $\beta=0.12, p=0.294$; fathers' involvement: $\beta=$ $0.05, p=0.647$; fathers' autonomy support: $\beta=-0.03$, $p=0.817$ ). Therefore, we did not proceed further to the mediation analysis for paternal support subscales.

We also conducted mediation analysis to investigate the mechanism between parental psychological control and academic achievement via goal disengagement by exploring the unique variances of the outcome variable associated with each subscale of parental psychological control scale (i.e., devaluation and guilt induction), separately for mothers and fathers. In step one of the causal steps approach (Baron and Kenny, 1986), the regression model using mothers' devaluation and mothers' guilt induction as predictors and academic achievement as the outcome showed that only mothers' devaluation was negatively associated with academic achievement (C-path: $\beta=-0.26, p=0.003$ ), while mothers' guilt induction was not (C-path: $\beta=0.07, p=$ $0.379)$. Therefore, only mothers' devaluation was used in the second step. Step two analysis showed that mothers' devaluation was positively associated with adolescents' goal disengagement (A-path: $\beta=0.20, p=0.004$ ), and adolescents' goal disengagement was negatively associated with academic achievement (B-path: $\beta=-0.19, p=0.004$ ). Mothers' devaluation was also negatively associated with academic achievement when goal disengagement was controlled in the model (C'-path: $\beta=-0.19, p=0.010$ ), indicating the relation was partially mediated by goal disengagement. The standardized indirect effect via the mediation was -0.04 and significant $(95 \%$ CI $[-0.081$, $-0.006]$ ) (Hayes, 2017). In addition to the statistically significant effect size of -0.04 , the final regression model explained $11.98 \%$ of the total variance in adolescents' academic achievement (Miočević et al., 2018).

In the total effect test on the association between subscales of paternal psychological control and academic control, fathers' guilt induction was negatively associated with academic achievement (C-path: $\beta=-0.18, p=0.031$ ), while fathers' devaluation was not (C-path: $\beta=-0.04, p=0.599$ ). The second step was conducted including only fathers' guilt induction, and the results showed that fathers' guilt induction was not significantly associated with goal disengagement (Apath: $\beta=-0.00, p=0.944$ ). Therefore, we did not proceed further to the next steps of mediation testing. Collectively, these results suggest that the association between mothers' devaluation and academic achievement is partially mediated by a significant indirect pathway via goal disengagement. On the other hand, goal disengagement was not a significant mediator of the relation between fathers' guilt induction and academic achievement.

\section{Alternative Direction Model}

Given the cross-sectional nature of the study, we conducted additional analyses to test whether the association among the variables of interests would be bidirectional. We tested multivariate mediation using goal engagement and goal disengagement as predictors, academic achievement as a mediator, and maternal support and maternal psychological control as outcome variables. The results showed that neither the standardized indirect effect from goal engagement to maternal support through academic achievement $(\beta=$ $0.04,95 \% \mathrm{CI}[-0.002,0.115])$ nor the standardized indirect effect from goal disengagement to maternal psychological control through academic achievement $(\beta=0.03,95 \%$ CI $[-0.006,0.061])$ were significant (Hayes, 2017). Therefore, the alternative model test revealed the relative robustness of the main model of the study.

\section{Discussion}

The significance of academic achievement during high school in determining higher education attainment has been rising (Galla et al., 2019; Geiser \& Santelices, 2007; Westrick et al., 2015), making it increasingly crucial that adolescents receive guidance and support from trustworthy and invested others such as parents (Eccles \& Roeser, 2009). Previous studies have demonstrated the role that parents play in supporting adolescents' education (Froiland \& Worrell, 2017; Veas et al., 2019; Xu et al., 2020). However, less is known about how academic goal engagement and disengagement mediate the relation between parenting and academic achievement. Our study contributes to the literature by revealing how parenting is indirectly associated with academic achievement via adolescents' own engagement and disengagement with school-related goals.

\section{Mediating Role of Goal Engagement for Maternal Support}

Supporting Hypothesis 1a, our mediation analyses showed that adolescents' goal engagement mediates the association between perceived maternal support and adolescents' academic performance. Goal engagement consists of investing significant time and energy to achieve a goal, while using self-motivating skills of reminding oneself of the value of a goal or imagining positive consequences of attaining a goal (Heckhausen et al., 2010). Our results show that the degree 
to which adolescents reported using goal engagement strategies was associated with maternal support. Furthermore, similar to previous studies (Hall et al., 2006; Hamm et al., 2013) our results demonstrate that the active use of goal engagement was positively associated with greater academic success as indicated by overall grades. Hence, our results suggest that maternal support is associated with higher academic achievement because this support encourages adolescents to use behavioral and cognitive motivational strategies that reflect high academic goal engagement. It is also notable that we found a full mediation pattern, which suggests the possibility that the change in the degree of goal engagement may be the primary pathway of maternal supports' association with academic achievement.

Our findings further indicate that while past studies have emphasized that various types of maternal support (i.e., showing warmth, spending time with the child, guiding the child towards independence) can benefit children and adolescents (e.g., Gordon \& Cui, 2012; Inguglia et al., 2015; Soenens \& Vansteenkiste, 2005), maternal warmth may be particularly important for academic goal engagement and achievement. Results from supplementary analyses showed that only maternal warmth significantly predicted academic goal engagement, reflecting prior studies which have shown that when parents express warmth towards their adolescent child, the child may feel that they are capable of achieving academic success (e.g., Hill \& Wang, 2015; Juang \& Silbereisen, 2002). Hence, mothers' warmth may provide adolescents with the self-efficacy beliefs that they need to become engaged with schoolwork and pursue their academic goals (Gurdal et al., 2016; Sun et al., 2020). Due to the high intercorrelations between mothers' warmth, involvement, and autonomy support, however, findings regarding maternal support sub-factors need to be interpreted with caution. Future studies should further examine the unique contribution of each parenting characteristic to adolescents' goal engagement and academic achievement.

\section{Goal Disengagement and Maternal Psychological Control}

We also found that goal disengagement strategies mediated the relation between maternal psychological control and academic achievement, which supported hypothesis $2 \mathrm{a}$ and is consistent with prior studies (Aunola \& Nurmi, 2004; Pinquart, 2016). Recent findings have shown that parental psychological control is linked with adolescents' uncertainty of their academic abilities (Lu et al., 2017; Xu et al., 2020). Adolescents who experience psychological control may develop low self-efficacy overtime in domains such as academics (e.g., Filippello et al., 2015). Our findings of the mediating role of adolescents' goal disengagement may have resulted from the negative effects of maternal psychological control on their self-efficacy, which renders a higher chance of disengagement from academic goals. Another possible negative effect of maternal psychological control could be adolescents' feelings of incompetence and lack of control, (Filippello et al., 2018), which may be associated with premature disengagement from their academic goals and ultimately a lower chance of achieving optimal academic performance.

Findings from the supplementary analysis on maternal psychological control sub-factors also suggest that the devaluation aspect of perceived maternal psychological control contributes to adolescents' tendency to disengage from academic goals. One study found that devaluing the child by invalidating the child's thoughts and expressions may lead to negative outcomes such as internalizing and externalizing behaviors (Symeou \& Georgiou, 2017). Extending this finding to academics, devaluation from mothers may also contribute to adolescents' low academic self-efficacy, which has been found to be associated with disengagement from their academic goals (Xu et al., 2020). When adolescents do not consider their own thoughts and behavior as valid and important, they may not believe that their actions lead to positive outcomes and consequently disengage from their academic goals, which may result in lower academic performance (Desjardins \& Leadbeater, 2017; Mandara \& Pikes, 2008). Regarding guilt induction, results showed that this component of maternal psychological control was not negatively associated with academic achievement. This finding suggests that though inducing guilt by bringing up past mistakes when criticizing the child or by blaming the child for others' problems is harmful for their psychological well-being (e.g., Rakow et al., 2009), it may not necessarily contribute as much as devaluation to adolescents' lack of persistence in pursuing and achieving their educational goals, especially when the sense of guilt was induced by mothers. Through examining the relation between different aspects of maternal psychological control and academics, our findings add to the existing literature by illustrating one possible process of how maternal psychological control is linked with students' disengagement, and ultimately to lower academic achievement.

\section{Differences in Mothers' and Fathers' Academic Influence}

In contrast with the findings regarding mothers' influence, paternal support and psychological control were only weakly associated with adolescents' academic achievement. Our results showed that only maternal support and psychological control were associated with goal engagement and disengagement, which in turn was linked to academic achievement. These findings indicate that mothers continue to be a stronger influence on adolescents' academic 
achievement than fathers. This is consistent with prior literature that has demonstrated greater academic-related involvement from mothers than from fathers (Hsu et al., 2011; Jeynes, 2015). However, these results may not necessarily suggest that fathers' warmth or psychological devaluation do not affect adolescents' developmental outcomes. Jeynes (2015) postulated that fathers may have a greater effect on youth's behavioral outcomes, but a smaller effect on their academic achievement. This aligns with our finding which indicated that fathers' guilt induction was significantly associated with lower academic achievements of adolescents, while mothers' guilt induction was not. These findings suggest that mothers and fathers may negatively contribute to adolescents' academic performance in different ways, and future studies should further examine potential mediating factors that explain the negative association between fathers' guilt induction and adolescents' academic achievement.

\section{Limitations}

There are several limitations in our study, the first being that this was a cross-sectional study. While the alternative model with reversed direction of association between parenting and academic achievement showed a weaker effect than the main model, we cannot confidently reject the possibility of a bidirectional relation between parenting and grades due to the lack of temporal precedence of the variables of interest. Second, our dataset did not contain information regarding prior academic achievement to be considered as a baseline measure. Future research should conduct longitudinal or experimental studies to confirm the direction of the associations between parenting, academic goal engagement and disengagement, and academic achievement. Third, as our sample size was relatively small with majority Latinx adolescents and only includes a specific point in time in a specific geographic location, the generalizability of our findings is potentially limited. Future studies with larger and more diverse samples would help establish the generalizability of our findings by examining whether demographic factors moderate the indirect effect of parenting on academic achievement. Fourth, the high amount of missing data for fathers' variables may have affected the results on paternal support and psychological control. We expect that if future research is conducted with larger samples, the relatively unpronounced role of paternal support and psychological control may be better captured. Finally, we used a collegestudent version of the scale to measure perceived parenting and adolescents' self-report of their experiences (i.e., perceived parental support, psychological control, grades). Having multiple observers assessing parent and child characteristics and multiple measures of academic achievement would help solidify the present findings.

\section{Conclusion}

Our study builds on the literature about parenting and adolescents' academic pursuits by examining ways in which parents may affect adolescents' academic achievement through impacting their use of motivational academic goal engagement and disengagement strategies. While maternal support through the expression of warmth predicts adolescents' engagement with academic goals that helps them attain better academic outcomes, maternal psychological control such as devaluation of the child is associated with adolescents' disengagement from academic goals which diminishes academic performance. These findings highlight the important role that mothers play in supporting adolescents' education by identifying ways to increase their academic success through developing their effort investment and persistence in school, and by helping them avoid pre-mature disengagement from their academic goals.

\section{Compliance with Ethical Standards}

Competing Interests The authors declare no competing interests.

Publisher's note Springer Nature remains neutral with regard to jurisdictional claims in published maps and institutional affiliations.

Open Access This article is licensed under a Creative Commons Attribution 4.0 International License, which permits use, sharing, adaptation, distribution and reproduction in any medium or format, as long as you give appropriate credit to the original author(s) and the source, provide a link to the Creative Commons license, and indicate if changes were made. The images or other third party material in this article are included in the article's Creative Commons license, unless indicated otherwise in a credit line to the material. If material is not included in the article's Creative Commons license and your intended use is not permitted by statutory regulation or exceeds the permitted use, you will need to obtain permission directly from the copyright holder. To view a copy of this license, visit http://creativecommons. org/licenses/by/4.0/.

\section{References}

Abar, B., Carter, K. L., \& Winsler, A. (2009). The effects of maternal parenting style and religious commitment on self-regulation, academic achievement, and risk behavior among AfricanAmerican parochial college students. Journal of Adolescence, 32(2), 259-273.

Aunola, K., \& Nurmi, J. E. (2004). Maternal affection moderates the impact of psychological control on a child's mathematical performance. Developmental Psychology, 40(6), 965.

Aunola, K., Stattin, H., \& Nurmi, J. E. (2000). Parenting styles and adolescents' achievement strategies. Journal of Adolescence, 23 (2), 205-222.

Barber, B. K. (1996). Parental psychological control: revisiting a neglected construct. Child Development, 67(6), 3296-3319.

Baron, R. M., \& Kenny, D. A. (1986). The moderator-mediator variable distinction in social psychological research: Conceptual, 
strategic, and statistical considerations. Journal of Personality and Social Psychology, 51(6), 1173.

Baumrind, D. (1966). Effects of authoritative parental control on child behavior. Child development, 887-907.

Boonk, L., Gijselaers, H. J., Ritzen, H., \& Brand-Gruwel, S. (2018). A review of the relationship between parental involvement indicators and academic achievement. Educational Research Review, 24, 10-30.

Brown, L., \& Iyengar, S. (2008). Parenting styles: the impact on student achievement. Marriage \& Family Review, 43(1-2), 14-38.

Desjardins, T., \& Leadbeater, B. J. (2017). Changes in parental emotional support and psychological control in early adulthood: direct and indirect associations with educational and occupational adjustment. Emerging Adulthood, 5(3), 177-190.

Dornbusch, S. M., Ritter, P. L., Leiderman, P. H., Roberts, D. F., \& Fraleigh, M. J. (1987). The relation of parenting style to adolescent school performance. Child Development, 1244-1257.

Eccles, J. S., \& Roeser, R. W. (2009). Schools, academic motivation, and stage-environment fit. Handbook of adolescent psychology, 1.

Englund, M. M., Luckner, A. E., Whaley, G. J., \& Egeland, B. (2004). Children's achievement in early elementary school: longitudinal effects of parental involvement, expectations, and quality of assistance. Journal of Educational Psychology, 96, 723-730. https://doi.org/10.1037/0022-0663.96.4.723.

Filippello, P., Harrington, N., Costa, S., Buzzai, C., \& Sorrenti, L. (2018). Perceived parental psychological control and school learned helplessness: the role of frustration intolerance as a mediator factor. School Psychology International, 39(4), 360-377.

Filippello, P., Sorrenti, L., Buzzai, C., \& Costa, S. (2015). Perceived parental psychological control and learned helplessness: the role of school self-efficacy. School Mental Health, 7(4), 298-310.

Freund, A. M., \& Baltes, P. B. (1998). Selection, optimization, and compensation as strategies of life management: correlations with subjective indicators of successful aging. Psychology and Aging, 13(4), 531.

Froiland, J. M., \& Worrell, F. C. (2017). Parental autonomy support, community feeling and student expectations as contributors to later achievement among adolescents. Educational Psychology, $37(3), 261-271$.

Fulton, E., \& Turner, L. A. (2008). Students' academic motivation: relations with parental warmth, autonomy granting, and supervision. Educational Psychology, 28(5), 521-534.

Galla, B. M., Shulman, E. P., Plummer, B. D., Gardner, M., Hutt, S. J., Goyer, J. P., \& Duckworth, A. L. (2019). Why high school grades are better predictors of on-time college graduation than are admissions test scores: the roles of self-regulation and cognitive ability. American Educational Research Journal, 56(6), 2077-2115.

Garcia, O. F., \& Serra, E. (2019). Raising children with poor school performance: parenting styles and short-and long-term consequences for adolescent and adult development. International Journal of Environmental Research and Public Health, 16(7), 1089.

Geiser, S., \& Santelices, M. V. (2007). Validity of high-school grades in predicting student success beyond the freshman year: highschool record vs. standardized tests as indicators of four-year college outcomes.

Gonida, E. N., \& Cortina, K. S. (2014). Parental involvement in homework: relations with parent and student achievement-related motivational beliefs and achievement. British Journal of Educational Psychology, 84(3), 376-396.

Gordon, M. S., \& Cui, M. (2012). The effect of school-specific parenting processes on academic achievement in adolescence and young adulthood. Family Relations, 61(5), 728-741.

Grolnick, W. S., Ryan, R. M., \& Deci, E. L. (1991). Inner resources for school achievement: Motivational mediators of children's perceptions of their parents. Journal of Educational Psychology, 83(4), 508-517.
Gurdal, S., Lansford, J. E., \& Sorbring, E. (2016). Parental perceptions of children's agency: Parental warmth, school achievement and adjustment. Early Child Development and Care, 186(8), 1203-1211.

Guay, F., Ratelle, C., Larose, S., Vallerand, R. J., \& Vitaro, F. (2013). The number of autonomy-supportive relationships: are more relationships better for motivation, perceived competence, and achievement? Contemporary Educational Psychology, 38(4), 375-382.

Hall, N. C., Chipperfield, J. G., Perry, R. P., Ruthig, J. C., \& Goetz, T. (2006). Primary and secondary control in academic development: gender-specific implications for stress and health in college students. Anxiety, Stress, and Coping, 19(2), 189-210.

Hamm, J. M., Stewart, T. L., Perry, R. P., Clifton, R. A., Chipperfield, J. G., \& Heckhausen, J. (2013). Sustaining primary control striving for achievement goals during challenging developmental transitions: the role of secondary control strategies. Basic and Applied Social Psychology, 35(3), 286-297.

Hayes, A. F. (2017). Introduction to mediation, moderation, and conditional process analysis: a regression-based approach. Guilford publications.

Heckhausen, J., \& Schulz, R. (1995). A life-span theory of control. Psychological Review, 102, 284-304.

Heckhausen, J., Schulz, R., \& Wrosch, C. (1998). Developmental regulation in adulthood: optimization in primary and secondary control-a multiscale questionnaire (OPS-Scales). Technical report.

Heckhausen, J., \& Tomasik, M. J. (2002). Get an apprenticeship before school is out: how German adolescents adjust vocational aspirations when getting close to a developmental deadline. Journal of Vocational Behavior, 60, 199-219.

Heckhausen, J., Wrosch, C., \& Schulz, R. (2010). A motivational theory of life-span development. Psychological Review, 117(1), 32.

Henry, C. S., Plunkett, S. W., \& Sands, T. (2011). Family structure, parental involvement, and academic motivation in Latino adolescents. Journal of Divorce \& Remarriage, 52(6), 370-390.

Hill, N. E. (2015). Including fathers in the picture: a meta-analysis of parental involvement and students' academic achievement. Journal of Educational Psychology, 107(4), 919.

Hill, N. E., Castellino, D. R., Lansford, J. E., Nowlin, P., Dodge, K. A., Bates, J. E., \& Pettit, G. S. (2004). Parent academic involvement as related to school behavior, achievement, and aspirations: Demographic variations across adolescence. Child Development, 75(5), 1491-1509.

Hill, N. E., \& Wang, M. T. (2015). From middle school to college: developing aspirations, promoting engagement, and indirect pathways from parenting to post high school enrollment. Developmental Psychology, 51(2), 224-235.

Hsu, H. Y., Zhang, D., Kwok, O. M., Li, Y., \& Ju, S. (2011). Distinguishing the influences of father's and mother's involvement on adolescent academic achievement: Analyses of Taiwan Education Panel Survey data. The Journal of Early Adolescence, 31 (5), 694-713.

Inguglia, C., Ingoglia, S., Liga, F., Coco, A. L., \& Cricchio, M. G. L. (2015). Autonomy and relatedness in adolescence and emerging adulthood: Relationships with parental support and psychological distress. Journal of Adult Development, 22(1), 1-13.

Jeynes, W. H. (2015). A meta-analysis: The relationship between father involvement and student academic achievement. Urban Education, 50(4), 387-423.

Juang, L. P., \& Silbereisen, R. K. (2002). The relationship between adolescent academic capability beliefs, parenting and school grades. Journal of Adolescence, 25, 3-18.

Komarraju, M., \& Nadler, D. (2013). Self-efficacy and academic achievement: Why do implicit beliefs, goals, and effort regulation matter? Learning and Individual Differences, 25, 67-72. 
Li, P., Stuart, E. A., \& Allison, D. B. (2015). Multiple imputation: a flexible tool for handling missing data. JAMA, 314(18), 1966-1967.

Little, R. J. (1998). A test of missing completely at random for multivariate data with missing values. Journal of the American statistical Association, 83(404), 1198-1202.

Lowe, K., \& Dotterer, A. M. (2013). Parental monitoring, parental warmth, and minority youths' academic outcomes: exploring the integrative model of parenting. Journal of Youth and Adolescence, 42(9), 1413-1425.

Lu, M., Walsh, K., White, S., \& Shield, P. (2017). The associations between perceived maternal psychological control and academic performance and academic self-concept in Chinese adolescents: the mediating role of basic psychological needs. Journal of Child and Family Studies, 26(5), 1285-1297.

Mandara, J., \& Pikes, C. L. (2008). Guilt trips and love withdrawal: Does mothers' use of psychological control predict depressive symptoms among African American adolescents? Family Relations, 57(5), 602-612.

Markazi, L., \& Badrigargari, R. (2011). The role of parenting selfefficacy and parenting styles on self-regulation learning in adolescent girls of Tabriz. Procedia-Social and Behavioral Sciences, 30, 1758-1760.

Miočević, M., O’Rourke, H. P., MacKinnon, D. P., \& Brown, H. C. (2018). Statistical properties of four effect-size measures for mediation models. Behavior Research Methods, 50(1), 285-301.

Monzani, D., Steca, P., Greco, A., D’Addario, M., Pancani, L., \& Cappelletti, E. (2015). Effective pursuit of personal goals: the fostering effect of dispositional optimism on goal commitment and goal progress. Personality and Individual Differences, 82, 203-214.

Niemiec, C. P., Lynch, M. F., Vansteenkiste, M., Bernstein, J., Deci, E. L., \& Ryan, R. M. (2006). The antecedents and consequences of autonomous self-regulation for college: a self-determination theory perspective on socialization. Journal of adolescence, 29 (5), 761-775.

Pinquart, M. (2016). Associations of parenting styles and dimensions with academic achievement in children and adolescents: a metaanalysis. Educational Psychology Review, 28(3), 475-493.

Pinquart, M., \& Ebeling, M. (2020). Parental educational expectations and academic achievement in children and adolescents - a Metaanalysis. Educational Psychology Review, 32, 463-480.

Poulin, M. J., \& Heckhausen, J. (2007). Stressful events compromise control strivings during a major life transition. Motivation and Emotion, 31(4), 300-311.

Rakow, A., Forehand, R., McKee, L., Coffelt, N., Champion, J., Fear, J., \& Compas, B. (2009). The relation of parental guilt induction to child internalizing problems when a caregiver has a history 'of depression. Journal of Child and Family Studies, 18(4), 367-377.

Roksa, J., \& Potter, D. (2011). Parenting and academic achievement: intergenerational transmission of educational advantage. Sociology of Education, 84(4), 299-321.

Rothermund, K., \& Brandstädter, J. (2003). Coping with deficits and losses in later life: from compensatory action to accommodation. Psychology and Aging, 18(4), 896.

Sangawi, H., Adams, J., \& Reissland, N. (2018). The impact of parenting styles on children developmental outcome: the role of academic self-concept as a mediator. International Journal of Psychology, 53(5), 379-387.

Shrout, P. E., \& Bolger, N. (2002). Mediation in experimental and nonexperimental studies: new procedures and recommendations. Psychological Methods, 7(4), 422-445.
Silinskas, G., Niemi, P., Lerkkanen, M. K., \& Nurmi, J. E. (2013). Children's poor academic performance evokes parental homework assistance-but does it help? International Journal of Behavioral Development, 37(1), 44-56.

Soenens, B., \& Vansteenkiste, M. (2005). Antecedents and outcomes of self-determination in 3 life domains: the role of parents' and teachers' autonomy support. Journal of Youth and Adolescence, 34(6), 589-604.

Sun, Y., Liu, R. D., Oei, T. P., Zhen, R., Ding, Y., \& Jiang, R. (2020). Perceived parental warmth and adolescents' math engagement in China: The mediating roles of need satisfaction and math selfefficacy. Learning and Individual Differences, 78, 101837.

Symeou, M., \& Georgiou, S. (2017). Externalizing and internalizing behaviours in adolescence, and the importance of parental behavioural and psychological control practices. Journal of Adolescence, 60, 104-113.

Tian, Y., Yu, C., Lin, S., Lu, J., Liu, Y., \& Zhang, W. (2019). Parental psychological control and adolescent aggressive behavior: deviant peer affiliation as a mediator and school connectedness as a moderator. Frontiers in Psychology, 10, 358.

Topor, D. R., Keane, S. P., Shelton, T. L., \& Calkins, S. D. (2010). Parent involvement and student academic performance: a multiple mediational analysis. Journal of Prevention \& Intervention in the Community, 38(3), 183-197.

Veas, A., Castejón, J. L., Miñano, P., \& Gilar-Corbí, R. (2019). Relationship between parent involvement and academic achievement through metacognitive strategies: A multiple multilevel mediation analysis. British Journal of Educational Psychology, 89(2), 393-411.

Wang, M. T., Hill, N. E., \& Hofkens, T. (2014). Parental involvement and African American and European American adolescents' academic, behavioral, and emotional development in secondary school. Child Development, 85(6), 2151-2168.

Wang, M., Deng, X., \& Du, X. (2018). Harsh parenting and academic achievement in Chinese adolescents: Potential mediating roles of effortful control and classroom engagement. Journal of School Psychology, 67, 16-30.

Wang, M. T., \& Sheikh-Khalil, S. (2014). Does parental involvement matter for student achievement and mental health in high school? Child Development, 85(2), 610-625.

Westrick, P. A., Le, H., Robbins, S. B., Radunzel, J. M., \& Schmidt, F. L. (2015). College performance and retention: a meta-analysis of the predictive validities of $\mathrm{ACT}^{\circledR}$ scores, high school grades, and SES. Educational Assessment, 20(1), 23-45.

Woolley, M. E., Kol, K. L., \& Bowen, G. L. (2009). The social context of school success for Latino middle school students: direct and indirect influences of teachers, family, and friends. The Journal of Early Adolescence, 29(1), 43-70.

Wrosch, C., \& Scheier, M. F. (2020). Adaptive self-regulation, subjective well-being, and physical health: the importance of goal adjustment capacities. In Advances in Motivation Science (Vol. 7, pp. 199-238). Elsevier.

Xiang, S., Liu, Y., \& Bai, L. (2017). Parenting styles and adolescents' school adjustment: investigating the mediating role of achievement goals within the $2 \times 2$ framework. Frontiers in Psychology, $8,1809$.

Xu, X., Dai, D. Y., Liu, M., \& Deng, C. (2020). Parental psychological control and academic functioning in Chinese high school students: a short-term longitudinal study. British Journal of Developmental Psychology, 38(1), 90-10. 